\title{
Isolated Peripheral Neuropathy in Atypical Metachromatic Leukodystrophy: A Recurrent Mutation
}

\author{
Marion B. Coulter-Mackie, Derek A. Applegarth, Jennifer R. Toone, \\ Liane Gagnier, André R. Anzarut, and Glenda Hendson
}

\begin{abstract}
Background: Metachromatic leukodystrophy (MLD) is a genetic neurodegenerative disorder resulting from a deficiency of arylsulfatase A. Late onset forms are relatively rare. Central nervous system (CNS) involvement is characteristic at all ages. Methods: A patient in her late 40s with peripheral neuropathy was assessed by EEG, evoked potentials, CTand nerve conduction studies. Nerve and muscle biopsy samples were investigated by electron microscopy. Arylsulfatase A activity in leukocytes and excreted cerebroside sulfate were determined. The arylsulfatase A gene was investigated for mutations using polymerase chain reaction (PCR) and DNAsequencing. The identified mutation was expressed transiently in African green monkey kidney (COS) cells to determine the effect of the mutation on arylsulfatase A activity. Results: Central nervous system functions were normal. Nerve conduction velocities were decreased. Sural nerve biopsy showed inclusions typical of MLD. Arylsulfatase A was less than $5 \%$ of normal. A homozygous mutation thr286pro was identified in the arylsulfatase A gene and demonstrated to be deleterious through transient expression studies. Conclusions: Our patient has a progressive peripheral neuropathy but has apparently intact CNS function at her present age of 57 years. Biochemical, physiological and pathological findings are consistent with a diagnosis of MLD. A homozygous mutation, thr286pro, found in her arylsulfatase A gene, decreased enzyme activity to a level consistent with a late onset form of MLD.
\end{abstract}

RÉSUMÉ: Neuropathie périphérique isolée dans la LDM atypique: mutation récurrente. Introduction: La leucodystrophie métachromatique (LDM) est une maladie neurodégénérative génétique résultant d'un déficit en arylsulfatase A. Les formes à début tardif sont relativement rares. L'atteinte du système nerveux central (SNC) est caractéristique quelque soit l'âge. Méthodes: Une patiente dans la quarantaine avancée, porteuse d'une neuropathie périphérique, a été évaluée par ÉEG, potentiels évoqués, CT et étude de la conduction nerveuse. Des spécimens nerveux et musculaires ont été étudiés par microscopie électronique. L'activité de l'arylsulfatase Ades leucocytes et l'excrétion de sulfate de cérébroside ont été déterminées. On a recherché des mutations dans le gène de l'arylsulfatase A par PCR et séquençage d'ADN. La mutation identifiée a été exprimée de façon transitoire dans des cellules COS pour déterminer l'effet de la mutation sur l'activité de l'arylsulfatase A. Résultats: Les fonctions du SNC étaient normales. Les vitesses de conduction nerveuse étaient diminuées. La biopsie du nerf sural a montré des inclusions typiques de la LDM. Le taux d'arylsulfatase Aétait à moins de 5\% du taux normal. Une mutation thr286pro à l'état homozygote a été identifiée dans le gène de l'arylsulfatase $\mathrm{A}$ et on a démontré son effet délétère par des études d'expression transitoire. Conclusions: Notre patiente était atteinte d'une neuropathie périphérique progressive avec préservation de la fonction du SNC à l'âge de 57 ans. Les évaluations biochimique, physiologique et anatomopathologique concordent avec un diagnostic de LDM. Une mutation thr286pro à l'état homozygote dans le gène de l'arylsulfatase Aa diminué l'activité enzymatique à un niveau compatible avec une forme tardive de LDM.

Can. J. Neurol. Sci. 2002; 29: 159-163

Metachromatic leukodystrophy (MLD) $^{1}$ is an autosomal recessive neurodegenerative disorder resulting from a deficiency of arylsulfatase A (aryl A), an enzyme responsible for normal lysosomal degradation of cerebroside sulfate (CS). Although the most common form is infantile, the age of onset may be as delayed as late middle age. The later onset forms of MLD commonly have psychiatric symptoms at the outset, then
From the Department of Pediatrics, University of British Columbia (MBC-M, DAA, JRT, LG) and Biochemical Diseases Laboratory, British Columbia's Children's Hospital; Department of Pathology and Laboratory Medicine (MBC-M, DAA, GH); Adult and Pediatric Neurology (ARA), University of British Columbia, Vancouver, British Columbia, Canada.

Received June 25, 2001. AcCepted infinalform December 5, 2001 Reprint requests to: MB Coulter-Mackie, BCCH, 4480 Oak St. Rm 2F22, Vancouver, British Columbia V6H 3V4 Canada. 
progress to physical symptoms similar to those seen in the earlier onset forms. The primary pathological changes in all forms are demyelination and deposition of metachromatic granules in the central nervous system (CNS) and peripheral nervous system. The biochemical findings are of reduced or absent aryl A activity, lysosomal storage of CS and urinary excretion of CS. Late onset MLD associated with isolated peripheral neuropathy has been documented rarely. ${ }^{2-4}$ Central nervous system involvement is characteristic in the vast majority of cases of late onset MLD.

We describe here a middle-aged female patient who has progressive peripheral neuropathy who has been followed clinically for at least 12 years with no obvious evidence of CNS involvement. She has reduced aryl A activity, increased urinary excretion of CS, decreased myelinated fibre density, axonal degeneration, partial remyelination and diagnostic inclusions in sural nerve biopsy, all consistent with a diagnosis of late onset MLD. She is homozygous for the mutation, thr286pro, in her aryl A gene. Since our initial report on this mutation 5 it has now been reported in a second much younger patient of similar ethnic background whose symptoms were similar, but of limited duration. ${ }^{4}$ The authors speculated that this was a deleterious mutation. We report here expression studies for this mutant enzyme that confirm that the thr286pro is indeed deleterious in decreasing the aryl A enzyme activity to a level roughly equivalent to that expected for a partial activity or late onset MLD mutation.

\section{Patient And Methods}

\section{Aryl A Assay}

Aryl A was assayed either in extracts of leukocytes ${ }^{6}$ or of cultured fibroblasts ${ }^{7}$ using a p-nitrocatechol sulfate substrate. Results are presented as nmoles nitrocatechol released / mg protein / hr. Aryl A, transiently expressed in COS cells, was assayed by a modification of the fibroblast method. ${ }^{8}$

\section{Polymerase chain reaction}

DNA samples were screened for the pseudodeficiency mutations and the common infantile and adult onset MLD mutations (IVS2+1, P426L) as previously described. ${ }^{9}$ A screen for single strand conformational polymorphisms was used to scan overlapping segments of the aryl A gene for potential mutations. ${ }^{9}$ Nucleotide numbering refers to the aryl A cDNA sequence (GenBank 52150) where nucleotide 1 is the first coding residue.

\section{Electron microscopy}

Sections were prepared by standard methods and stained for electron microscopy (EM) with uranyl acetate and lead citrate.

\section{Patient description}

The patient is a woman of Punjabi descent who presented at age 47 with cramping in her lower limbs and, to a lesser extent, her hands. She was otherwise well. She displayed symmetrical weakness and decreased sensation in her upper and lower limbs bilaterally. She had generalized areflexia. At her first assessment, EEG, visual evoked potential, somatosensory evoked potentials, and brainstem auditory evoked potentials, and CT scan were all normal suggesting a lack of CNS involvement. The peripheral symptoms have worsened over a 10 year period but do not appear to have progressed to include CNS involvement. Her cognitive function is considered normal and she is still employed at age 57. There is no clinical or electrophysiological evidence of CNS involvement. An MRI scan would provide a definitive picture of the status of the patient's CNS but this has not been performed to date. The patient has an older brother who reportedly suffers similar problems with his hands and feet.
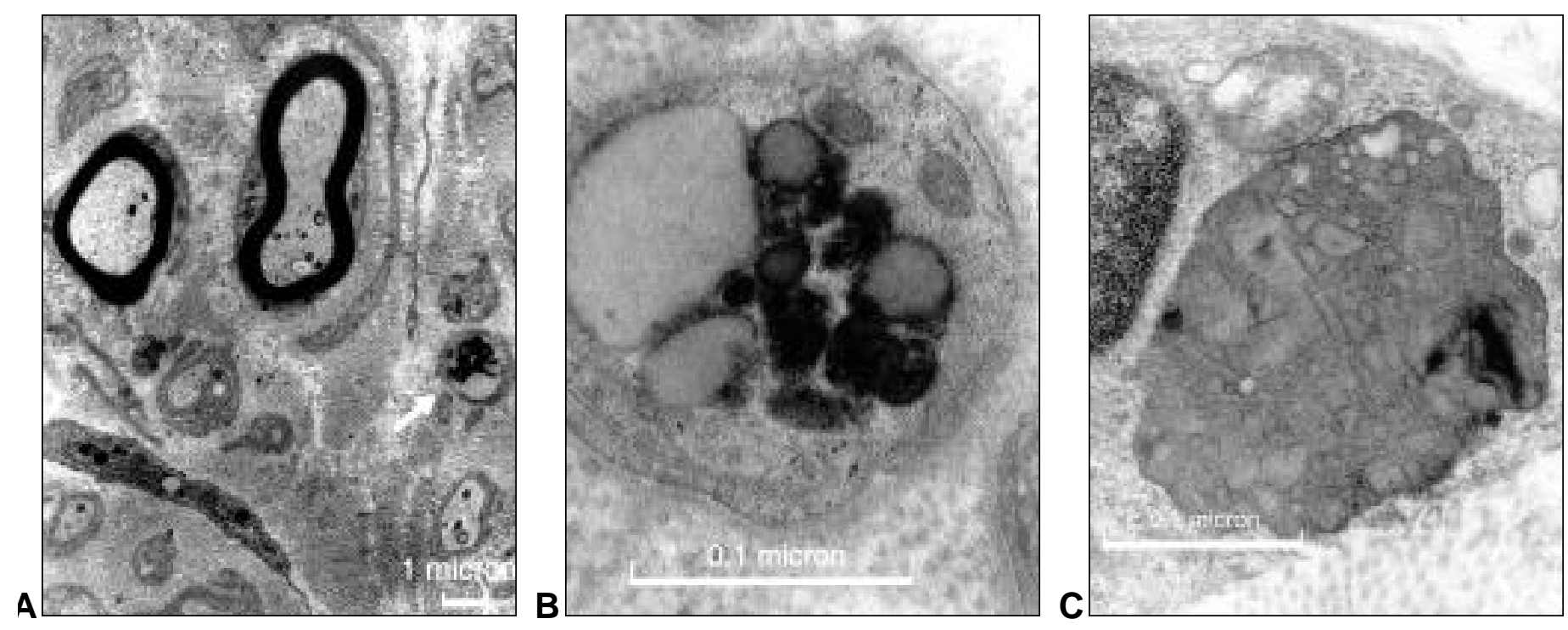

Figure: Electron microscopy of sural nerve biopsy. A. The section includes myelinated axons, unmyelinated axons and fibroblasts. The arrow indicates an unmyelinated axon with intracellular inclusions in the Schwann cell cytoplasm. B. Higher magnification of the unmyelinated axon and inclusions in Schwann cell cytoplasm. C. High magnification of a macrophage showing prismatic inclusion bodies. 
Table 1: Nerve Conduction Studies*

\begin{tabular}{|c|c|c|c|c|c|}
\hline \multirow[b]{3}{*}{ Motor Nerves } & \multicolumn{4}{|c|}{ Year } & \multirow{3}{*}{$\begin{array}{l}\text { Normal } \\
\text { Values } \\
\text { MCV } \\
\mathbf{m} / \mathbf{s e c}\end{array}$} \\
\hline & \multicolumn{2}{|c|}{1988} & \multicolumn{2}{|c|}{1995} & \\
\hline & $\begin{array}{l}\text { MCV } \\
\text { m/sec }\end{array}$ & $\begin{array}{c}\text { amplitude } \\
\mathrm{mV}\end{array}$ & $\begin{array}{l}\text { MCV } \\
\mathrm{m} / \mathrm{sec}\end{array}$ & $\begin{array}{l}\text { amplitude } \\
\text { mV }\end{array}$ & \\
\hline $\begin{array}{l}\text { Median } \\
\text { (elbow to wrist) }\end{array}$ & 20 & 10 & 24 & 1 & $>50$ \\
\hline F-wave & & $9 \mathrm{~ms}$ & & & $<32.5$ \\
\hline $\begin{array}{l}\text { Ulnar } \\
\text { (elbow to wrist) }\end{array}$ & 24 & 3.5 & 29 & 3 & $>50$ \\
\hline F-wave & & $7 \mathrm{~ms}$ & & & $<32.5$ \\
\hline $\begin{array}{l}\text { Peroneal } \\
\text { (knee to ankle) }\end{array}$ & 20 & 3.0 & no response & & $>40$ \\
\hline F-wave & & $8 \mathrm{~ms}$ & no response & & $<62.5$ \\
\hline Sensory Nerves & $\begin{array}{l}\text { SCV } \\
\mathrm{m} / \mathrm{sec}\end{array}$ & $\begin{array}{c}\text { amplitude } \\
\mu \mathrm{V}\end{array}$ & $\begin{array}{l}\text { SCV } \\
\mathrm{m} / \mathrm{sec}\end{array}$ & $\begin{array}{c}\text { amplitude } \\
\mu \mathrm{V}\end{array}$ & $\begin{array}{l}\text { SCV } \\
\text { m/sec }\end{array}$ \\
\hline $\begin{array}{l}\text { Median } \\
\text { (wrist to F2) }\end{array}$ & 31 & 17 & 28 & 5 & $>50$ \\
\hline $\begin{array}{l}\text { Ulnar } \\
\text { (wrist to F5) }\end{array}$ & 28 & 20 & 26 & 5 & $>50$ \\
\hline $\begin{array}{l}\text { Sural } \\
\text { (calf to ankle) }\end{array}$ & 22 & 5 & no response & & $>40$ \\
\hline
\end{tabular}

*Measurements were taken at ambient temperature.

\section{RESUlts}

\section{Electrophysiology and neuropathology findings}

Nerve conduction studies were performed several times over the last 12 years. Results summarized in Table 1 demonstrate marked slowing of conduction velocity in both motor and sensory fibers of upper and lower limbs. The clinical and neurophysiological examination were consistent with a severe generalized peripheral sensory and motor neuropathy of a demyelinating type.

Gastrocnemius muscle biopsy showed evidence of neurogenic atrophy with re-innervation. No ultrastructural abnormalities were seen on EM. Microscopic examination of a sural nerve biopsy showed decreased density of myelinated fibers with evidence of demyelination and partial remyelination. The most striking feature was seen on EM as cytoplasmic inclusions in Schwann cell cytoplasm of myelinated and unmyelinated axons as well as in scattered macrophages. The inclusions resembled zebra bodies, tuffstone bodies and laminated collections of fine disc-like structures. Figure (A and B) show a representative field illustrating tuffstone bodies. These are strongly reminiscent of CS storage inclusions seen in MLD. ${ }^{10,11}$ Striking prismatic inclusions were seen in the macrophages (Figure $\mathrm{C}$ ). These are considered a diagnostic feature of MLD. ${ }^{12}$

\section{Biochemical findings}

Biochemical assessment of the patient and family members for aryl A (Table 2) showed she had about $5 \%$ of the normal control mean leucocyte aryl A. Enzyme levels of both her parents and her daughter were in a probable carrier range although we expect to find some overlap between MLD obligate heterozygotes and normal control values. The son's enzyme level was intermediate between the carriers and his mother. Subsequent aryl A assay in the patient's cultured fibroblasts showed about $11 \%$ of normal acitivity. The residual activity in fibroblast extracts was sufficient to determine a $\mathrm{Km}$ of $2.1 \mathrm{mM}$ which was comparable to a normal sample tested in parallel.

Table 2: Biochemical and Molecular Characteristics of Family Members

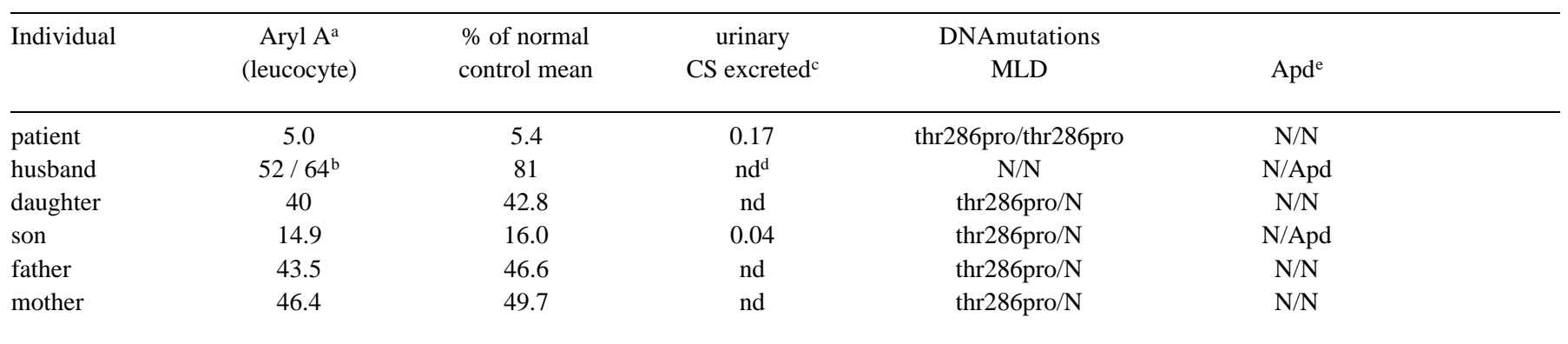

a leucocyte aryl A units given as nmoles nitrocatechol released/mg protein/hour normal value: mean 71.6; range 42.5-165

b normal value: mean 93.4; range 41-234

c CS (cerebroside sulfate) excreted given as nm/mg creatinine; normal value 0.03-0.1. Determined in the Biochemistry Laboratory of the Hospital for Sick Children, Toronto, Canada.

d nd=none detected

e Apd represents both pseudodeficiency mutations 
Cerebroside sulfate excretion was higher than the normal range in the patient urine (see Table 2).

On the basis of the neurophysiological, neuropathological and biochemical findings, a diagnosis of atypical late onset MLD was made.

\section{Molecular analysis}

The common early and late onset MLD mutations were absent in this patient. Both the husband and the son were carriers of the pseudodeficiency mutations (Apd). Single strand conformational polymorphisms screening and subsequent DNA sequencing of the patient's DNA revealed a homozygous transversion, $\mathrm{A} 856 \mathrm{C}$, in exon 5 that would result in a thr286pro missense mutation. Both children, as well as the patient's parents were heterozygous carriers of this mutation. These results are summarized in Table 2. The son's Apd/MLD carrier genotype accounted for his aryl A levels being lower than that of his sister or grandparents. The A856C mutation was associated with the most common haplotype of intragenic polymorphisms, BsrI(1)BamHI(1)-NlaIII ${ }^{1}(1)-$ NlaIII $^{2}-(1) .{ }^{13}$

\section{Site-directed mutagenesis and transient expression}

The A856C mutation was introduced into the pSVl-aryl A expression vector by unique site elimination. ${ }^{14}$ The mutant vector was transfected into COS cells as described previously. ${ }^{9}$ The resultant aryl Aactivity after correction for endogenous aryl A and transfection efficiency was $15 \%$ of that seen for a parallel wild-type pSVl-aryl A plasmid. For comparison, an infantile onset MLD mutation, $\mathrm{A} 212 \mathrm{~V}$, tested in parallel, showed less than 5\% compared to the wild type. This level of residual activity is equivalent to that normally seen in mutations causing adult onset MLD.

\section{DISCUSSION}

The level of residual aryl A activity seen in the patient and in the transient expression system suggests that thr286pro is a partial activity mutation. Thr286 follows a conserved region in aryl $\mathrm{A}^{1}$ but is itself minimally conserved. Thr286 appears at the corresponding location in human arylsulfatase $\mathrm{B}$ and $\mathrm{N}$ acetylglucosamine-6-sulfate sulfatase but not in the other human sulfatases $^{1}$ and not in mouse aryl A. ${ }^{15}$ The 3-dimensional structure of aryl A suggests thr286 is part of an amino acid sequence connecting regions with significant secondary structure and does not appear to be directly involved in the active site or regions important for dimerization. ${ }^{16}$ Introduction of a proline residue might be expected to disrupt normal secondary structure. The normal $\mathrm{Km}$ seen for the patient's residual aryl A activity suggests there is no alteration in substrate binding. All these observations are consistent with a partial deficiency causing a mild late onset MLD. Thr286pro behaves like a true MLD mutation rather than a novel pseudodeficiency mutation since the patient excretes urinary CS slightly above normal levels and shows stored material in a nerve biopsy sample.

Adult onset MLD may be manifest as early as 14 and as late as 62 years of age. ${ }^{1}$ Psychiatric problems are the most common initial symptom and the disease may be mistaken for schizophrenia, Alzheimer's disease, or depression. ${ }^{17-20}$ It has been observed that symptoms of peripheral neuropathy may not be obvious clinically although they will be evident on nerve conduction studies. ${ }^{21,22}$ Isolated peripheral neuropathy associated with late onset MLD may be mistaken for Charcot-Marie-Tooth disease in the absence of EM studies and biochemical analyses.

Three cases have been reported where peripheral neuropathy was the sole presenting problem. ${ }^{2-4}$ In the first two cases (ages 38 and 45), the Apd allele was absent but no other causative mutation was identified. The most recent case ${ }^{4}$ was very similar to our own. The levels of aryl A activity were reduced but still significant in both cases. Both the case reported by Felice et $\mathrm{al}^{4}$ and our own were homozygous for the same thr286pro mutation. Our expression studies confirmed this mutation as a partial activity mutation consistent with a late onset for MLD.

Our patient did not present until her late 40s and has since followed a slowly progressive course of peripheral neuropathy over 12 years of observation. This is in contrast to the other case ${ }^{4}$ where the patient was a young adult, age 22, whose symptoms resolved after one year. It will be interesting to see how this case develops as the young man ages.

Both our case and the previous one occurred in individuals of Asian/Indian descent. On the basis of only two cases we can only speculate about ethnic correlations especially since this atypical late onset disease may well be under-diagnosed given the mildness of symptoms.

\section{ACKNOWLEDGEMENTS}

This work was supported by a grant to MBCM from the British Columbia Health Research Foundation. We thank Ms. Christina Singh for assistance in obtaining patient samples.

\section{REFERENCES}

1. Kolodny EH, Fluharty AL. Metachromatic leukodystrophy and multiple sulfatase deficiency:sulfatide lipidosis. In: Scriver CR, Beaudet AL, Sly WS, et al, eds. The Metabolic and Molecular Bases of Inherited Disease. 7th ed. v. 2. New York: McGraw-Hill, Inc., 1995: 2693-2739.

2. Fressinaud C, Vallat JM, Masson M, et al. Adult-onset metachromatic leukodystrophy presenting as isolated peripheral neuropathy. Neurology 1992; 42: 1396-1398.

3. Hansen LM, Kristensen O, Friis ML. Neuropathy in adult metachromatic leukodystrophy. Ugeskr Laeger 1994; 156: 22522253.

4. Felice KJ, Gomez Lira M, Natowicz M, et al. Adult-onset MLD A gene mutation with isolated polyneuropathy. Neurology 2000; 55:1036-1039.

5. Coulter-Mackie MB, Gagnier L, Applegarth DA, Toone J. A unique homozygous mutation in the arylsulfatase A gene of a patient with a late onset peripheral neuropathy. Am J Hum Genet 1996; (Suppl 4):1467.

6. Baum H, Dodgson KS, Spencer B. The assay of arylsulfatases A and B in human urine. Clin Chim Acta 1959; 4: 453-455.

7. Lee-Vaupel M, Conzelmann E. A simple chromogenic assay for arylsulfatase A. Clin Chim Acta 1987; 164: 171-180.

8. Rip J, Gordon BA. A simple spectrophotometric enzyme assay with absolute specificity for arylsulfatase A. Clin Biochem 1998; 31 : 29-31.

9. Coulter-Mackie MB, Gagnier L, Beis MJ, et al. Metachromatic leucodystrophy in three families from Nova Scotia, Canada: a recurring mutation in the arylsulphatase A gene. J Med Genet 1997; 34: 493-498.

10. Argyrakis A, Pilz H, Goebel HH, Müller D. Ultrastructural findings of peripheral nerve in a preclinical case of adult metachromatic leukodystrophy. J Neuropathol Exp Neurol 1977; 36: 693-711.

11. Thomas PK, King RHM, Kocen RS, Brett EM. Comparative ultrastructural observations on peripheral nerve abnormalities in the late infantile, juvenile and late onset forms of metachromatic leukodystrophy. Acta Neuropath 1977; 39: 237-245. 
12. Friede RL. Metachromatic leukodystophy (sulfatase A deficiency) and multiple sulfatase deficiency. In: Friede RL (ed). Developmental neuropathology. Germany: Springer-Verlag, 1989: 460-469.

13. Coulter-Mackie MB, Gagnier L. Two new polymorphisms in the arylsulfatase $\mathrm{A}$ gene and their haplotype associations with normal, metachromatic leukodystrophy and pseudodeficiency alleles. Am J Med Genet 1997; 73: 32-35.

14. Deng WP, Nickoloff JA. Site-directed mutagenesis of virtually any plasmid by eliminating a unique site. Ann Biochem 1992; 200:81-88

15. Kreysing J, Polten A, Hess B, et al. Structure of the mouse arylsulfatase A gene and cDNA. Genomics 1994; 19: 249-256.

16. Lukatela G, Krauss N, Theis K, et al. Crystal structure of human arylsulfatase A: the aldehyde function and the metal ion at the active site suggest a novel mechanism for sulfate ester hydrolysis. Biochemistry 1998; 37: 3654-3664.
17. Hyde TM, Ziegler JC, Weinberger DR. Psychiatric disturbances in metachromatic leukodystrophy. Arch Neurol 1992; 49: 401-406.

18. Sadovnick AD, Tuokko H, Applegarth DA, et al. The differential diagnosis of adult onset metachromatic leukodystrophy and early onset familial Alzheimer's disease in an Alzheimer clinic population. Can J Neurol Sci 1993; 20: 312-318.

19. Baumann N, Masson M, Carreau V, et al. Adult forms of metachromatic leukodystrophy: clinical and biochemical approach. Dev Neurosci 1991; 13: 211-215.

20. Perusi C, Lira MG, Duyff RF, et al. Mutations associated with very late onset metachromatic leukodystrophy. Clin Genet 1999;55:130.

21. Wulff $\mathrm{CH}$, Trojaborg W. Adult metachromatic leukodystrophy: neurophysiologic findings. Neurology 1985; 35: 1776-1778.

22. Hageman ATM, Gabreëls FJM, de Jong JGN, et al. Clinical symptoms of adult metchromatic leukodystrophy and arylsulfatase A pseudodeficiency. Arch Neurol 1995; 52: 408413. 